\title{
A NOVA PROPOSTA CURRICULAR DO ESTADO DE SÃO PAULO: LIMITES E VIRTUDES
}

Rafael Moreno Castellani, Universidade Estadual de Campinas - UNICAMP, Campinas, São Paulo - Brasil

\section{RESUMO}

Como iniciativa política de maior impacto da SEE/SP foi desenvolvida uma Proposta Curricular para a Educação Básica. Após sua consolidação, apontar o entendimento dos educadores físicos sobre as virtudes e limitações da proposta, além de analisar a proposta em suas duas dimensões políticas (modelo teórico e implementação/execução) foram objetivos deste estudo. Entrevistamos nove professores efetivos e estáveis da Rede Pública Estadual Paulista e um dos professores responsáveis pela construção da Proposta Curricular. Concluímos que a Proposta apresenta virtudes e limitações em seu modelo conceitual e implementação/execução. Superar tais limitações e aprimorar suas virtudes é o que busquei sinalizar propositivamente.

Palavras-Chave: Política educacional; Proposta curricular; Educação Física.

\section{THE NEW CURRICULAR PROPOSAL FOR THE STATE OF SÃO PAULO: LIMITS AND VIRTUES}

\begin{abstract}
As a political initiatives of higher impact of the SEE/SP it has been developed a New Curricular Proposal for Elementary and High school. After its consolidation, to point the acknowledgment of the physical educators about the virtues and limitations of the proposal, besides analyzing the proposal in its two politics dimensions (theoretical model and implementation/execution) have been the objective of this study. We interviewed nine effective and stable professors from State Public Network of São Paulo and one of the responsible professors for the construction of the Curriculum Proposal. We conclude that the Proposal in such a way presents virtues and limitations in its conceptual model as well as in the implementation and execution. To overcome those limitations and to improve its virtues, is what I positively tried to signal.
\end{abstract}

Key-Words: Educational politics; Curriculum proposal; Physical Education. 


\section{LA NUEVA PROPUESTA DE PLAN DE ESTUDIOS DEL ESTADO DE SÃO PAULO: VIRTUDES Y LIMITACIONES}

\section{RESUMEN}

Como iniciativa política de mayor impacto de la ESS/SP fue desarrollada una Nueva Propuesta de Plan de Estudios para Educación Básica. Después de su consolidación, apuntar la comprensión de los educadores físicos sobre las virtudes y limitaciones de la propuesta además de examinar la propuesta en sus dos dimensiones políticas (modelo teórico, implementación y ejecución) fueron objetivos de este estudio. Entrevistamos nueve profesores efectivos y estables de la Red Pública Paulista y uno de los profesores responsables por la construcción del Plan de Estudios. Se concluye que la propuesta tiene virtudes y limitaciones, tanto en su modelo conceptual quanto en la aplicación/cumplimiento. Superar estas limitaciones y aprimorar sus virtudes es lo que he buscado señalar propositivamente.

Palabras-Clave: Política educacional, Propuesta de plan de estudios, Educación Física. 


\section{INTRODUÇÃO}

Sob a responsabilidade de gestão da Secretaria Estadual de Educação do Estado de São Paulo (SSE/SP), implementou-se a partir de julho de 2007 uma política educacional muito questionada pelos professores da Rede, em reuniões pedagógicas, encontros nas Diretorias de Ensino e comunicados dos sindicatos da categoria. Dentre as propostas ${ }^{1}$, mereceu maior destaque a construção de um novo currículo que atendesse ao segundo ciclo do ensino fundamental e ensino médio, o processo de avaliação dos professores por mérito e a bonificação por desempenho. Suas ações demonstraram uma compreensão de gestão de política pública centralizadora, autoritária e não participativa, já que não procurou contar com a participação da comunidade, instâncias representativas (sindicatos) e professores.

Uma gestão política que, acima de tudo, desvaloriza o professor, subestimando sua capacidade e importância. Uma visão que entende, conforme Valente, ${ }^{1}$ ser um mito a necessidade de isonomia salarial entre professores, que melhores salários levam à melhoria do ensino, que o número de alunos em sala de aula interfere na qualidade do aprendizado e que a escola pública é carente de recursos. Em entrevista à Folha Online ${ }^{2}-$ um dia antes da sua posse - a futura Secretária de Educação apontou como objetivos de sua gestão "dar a continuidade do esforço para melhorar a alfabetização, ênfase no uso das avaliações para melhorar a qualidade da aprendizagem, aperfeiçoamentos na gestão do sistema e atenção especial na formação e valorização dos professores".

Para o período letivo, a SSE/SP construiu para o ano de 2008 uma Nova Proposta Curricular (NPC) para o ensino público estadual da $5^{\mathrm{a}}$ série do ensino fundamental (atual $6^{\mathrm{o}}$ ano) ao $3^{\mathrm{o}}$ ano do ensino médio (FINI, 2008). ${ }^{3}$ Castro, ${ }^{4: \mathrm{A} 03} \mathrm{em}$ artigo à Folha Online supracitado, afirma que:

[...] os professores terão uma base comum para o ensino em sala de aula. Terão um guia seguro com indicações e sugestões de trabalho. Para cada aula haverá indicação do que os alunos precisam aprender. Essa proposta curricular contou com a participação de toda a rede, com 3000 idéias.

\footnotetext{
${ }^{1}$ Somente a primeira proposta exemplificada, ou seja, a proposta curricular, será analisada neste estudo.

Conexões: revista da Faculdade de Educação Física da UNICAMP, Campinas, v. 11, n. 1, p. 235-251, jan../mar. 2013.237 ISSN: 1983-9030
} 
Suas características, virtudes e limitações serão expostas neste momento; tendo como exemplo o componente curricular Educação Física (EF). Antes, vale salientar que processos semelhantes foram vivenciados décadas passadas. Na década de 80 , a proposta pedagógica de João Batista Freire - contrapondo Ana Maria Pelegrine - a de Lino Castellani Filho, do inicio da década de 90, e a do professor Go Tani, no final da década de 90, caracterizaram os momentos mais marcantes das propostas pedagógicas em Educação Física neste período ${ }^{2}$. Em nível nacional, vale destacar a elaboração dos Parâmetros Curriculares Nacionais (PCNs), cuja função principal era subsidiar a elaboração de currículos para os Estados e Municípios. ${ }^{5}$

Em 2008, sob a tutela de Jocimar Daólio, Mauro Betti, Luciana Venâncio e Luiz Sanches, a construção da nova Proposta Curricular de Educação Física, ${ }^{7-8}$ visava atender de 5.000 a 6.000 escolas e mais de 15.000 professores com a construção de 28 cadernos "didáticos"” anuais e 8 vídeo-aulas.

Passados três anos de implementação da nova proposta curricular - em 2009 passou a ser chamada de Currículo Oficial - foi objetivo deste estudo apontar o entendimento dos professores de educação física da rede pública estadual paulista de ensino sobre as virtudes e limitações da proposta, retratar as características das aulas de educação física neste contexto para analisar as características da nova proposta curricular em suas duas dimensões políticas: modelo conceitual e implementação/execução. Justifico tal opção por entender que tais dimensões compõem momentos distintos de uma mesma proposta política e dessa forma devem ser analisadas separadamente. Ou seja, o modelo teórico pode ser de muita qualidade, mas por deficiências na sua execução, fica evidenciada sua fragilidade como um todo, ou vice-versa.

\footnotetext{
${ }^{2}$ Informações retiradas em comunicações pessoais com o professor Lino Castellani Filho em 05 de Abril de 2010 e em artigo intitulado "Proposta curricular de $1^{a}$.a $4^{a}$.série do ensino fundamental", escrito por Silveira $(2010)^{6}$, disponibilizado no site da SEE/CENP. Ressalto que não é objetivo deste artigo caracterizar/descrever tais propostas.

${ }^{3}$ Mantenho entre aspas a palavra didático, pois o caderno de atividades proposto não atende às necessidades e características de um material didático propriamente dito.

Conexões: revista da Faculdade de Educação Física da UNICAMP, Campinas, v. 11, n. 1, p. 235-251, jan../mar. 2013.238 ISSN: 1983-9030
} 
Apesar da NPC estar presente em todas as escolas estaduais paulistas cabendo, portanto, à todos os professores a execução da mesma, participaram deste estudo nove professores ${ }^{4}$ efetivos e estáveis da Rede Pública Estadual de Ensino de municípios situados no interior do Estado de São Paulo e analisadas as particularidades de três escolas (das quais tive oportunidade de atuar como docente de educação física) que me permitiram ter uma leitura mais profunda e rigorosa das possibilidades de implementação e execução da nova proposta. Uma entrevista com um dos professores responsáveis por elaborar e construir a Proposta Curricular de Educação Física, Jocimar Daólio ${ }^{5}$, me permitiu uma leitura mais crítica a respeito do modelo conceitual adotado, assim como os métodos utilizados para construí-la e executá-la na rede pública estadual de ensino.

\section{O DEPOIMENTO DE PROFESSORES}

Foram entrevistados ao todo nove professores de educação física, em consentimento com a participação no estudo, pertencentes à rede pública estadual de ensino que atendessem à diretoria de ensino do município de Limeira e Campinas (interior do Estado de São Paulo).

As perguntas pautavam-se no entendimento dos professores a respeito das virtudes e limites da NPC implementada em todo Estado. As escolas analisadas atendem à Diretoria de Ensino de Campinas e Limeira, sendo duas escolas delas da própria cidade de Limeira e uma terceira de Iracemápolis ${ }^{6}$.

Dentre as virtudes da proposta, as mais apontadas pelos professores entrevistados foram: Conteúdos diversificados e ricos (maior suporte e base para o aluno); igualar o ensino de educação física em todo o Estado; e a articulação de novas propostas.

\footnotetext{
${ }^{4}$ Os professores foram selecionados conforme dois critérios: proximidade geográfica que viabilizasse as entrevistas; e principalmente que demonstrassem conhecimento da proposta, refletido na sua atuação docente com alunos do ensino fundamental e médio de escola pública estadual paulista, prática essa observada antes da seleção.

${ }^{5}$ Como um dos professores responsáveis pela elaboração da proposta e não representando a opinião dos demais, o professor Jocimar Daólio autorizou a divulgação do seu nome para este artigo.

6 Campinas, Limeira e Iracemápolis são cidades do interior do Estado de São Paulo que estão respectivamente a aproximadamente 80,120 e $140 \mathrm{~km}$ da capital.

Conexões: revista da Faculdade de Educação Física da UNICAMP, Campinas, v. 11, n. 1, p. 235-251, jan../mar. 2013.239 ISSN: 1983-9030
} 
Manifestada por sete dos nove professores entrevistados (representando aproximadamente $78 \%$ do total) a existência de conteúdos diversificados e ricos vieram para motivar os alunos e fornecer a eles um maior suporte e base para seu conhecimento.

\footnotetext{
"A virtude está na diversificação das atividades... Antes era muito focado nos quatro esportes coletivos". (Professor 6)
}

Em seguida, apontado por três dos nove professores entrevistados (cerca de 33\%), a criação de uma nova proposta se faz importante por tentar melhorar e mudar as características das aulas de EF.

"Na minha opinião, sempre é bem vinda uma nova proposta, textos para serem trabalhados". (Professor 1)

Com os mesmos 33\%, o fato da proposta igualar o ensino de educação física em todo Estado foi apontado como grande virtude. Entende-se que assim os alunos não serão prejudicados quanto aos conhecimentos adquiridos se precisar mudar de escola, seja na mesma cidade, ou em cidades diferentes do Estado.

"Eu vejo que ela busca igualar o ensino de educação física em todo o
Estado de São Paulo porque antes era muito difuso... Tenta fazer que com
os professores usem os conteúdos de uma forma única". (Professor 2)
"É importante a nossa área ter um currículo que seja colocado em prática
em todo Estado". (Professor 7)

Presentes também nos discursos dos professores, porém em menor proporção, foram ressaltadas como virtudes a qualidade do material (com bons textos e boa aparência) podendo por meio do seu referencial teórico suprir a defasagem do professor, o debate de currículo para educação física (entretanto sem a presença de professores da rede) e a maior incidência de aulas teóricas - importantes por fundamentar a prática do educando.

"Eu acho que as aulas teóricas vieram pra fundamentar um pouco mais. Pra poder fazer com que a garotada se incentive um pouco mais a escrever, a ler". (Professor 5) 
Por sua vez, dentre os limites da nova proposta curricular levantados pelos professores entrevistados, os mais presentes são: Conteúdos distantes da realidade; organização $e$ sistematização dos conteúdos; e ausência de diálogo e interlocução entre construtores da proposta, demais pesquisadores e professores da rede.

Conforme sete dos nove professores entrevistados (cerca de 78\%), os conteúdos presentes na proposta estão muitos distantes da realidade das escolas públicas estaduais. Faltam recursos físicos e materiais em grande parte das escolas do Estado de São Paulo. Ainda a esse respeito, $22 \%$ dos professores entrevistados enfatizaram a ausência de conteúdos importantes para EF.

"É uma proposta totalmente fora da realidade, só faltou aula de natação! Temas como o zuki ou algo parecido são difíceis de aceitação e é um desgaste desnecessário para os professores. Sempre que propor algo, a secretaria deveria dar condições materiais e físicas". (Professor 3)

"O problema é falta de material. Você precisa e não tem como usá-lo". (Professor 4)

Segundo limite mais freqüente (cerca de 55,5\%) no discurso dos professores refere-se à organização e sistematização dos conteúdos. Apesar de elogiada a diversidade de conteúdos, a extensa presença deles em períodos muito curtos impossibilitam os professores de cumprirem à risca a proposta e transmitirem o conhecimento com qualidade.

"A proposta é grande e nem sempre agente consegue vencer todo conteúdo conforme está no caderninho lá os limites das aulas". (Professor 9)

Aproximadamente 44,5\% dos professores entrevistados destacam a ausência de diálogo entre elaboradores da proposta, demais pesquisadores e professores da rede na construção e formulação da proposta. Isso acaba por distanciá-la ainda mais da realidade das escolas públicas estaduais dificultando o desenvolvimento do trabalho do professor de maneira a cumprir, com competência, o sugerido pela NPC.

"A principal limitação é a forma vertical e autoritária da imposição do material sem o devido debate com quem vai de fato trabalhar". (Professor 3) 
"Acho que deveria ter tido uma consulta aos professores e outros pesquisadores e cientistas da área antes de ser adotada como uma verdade objetiva a ser trabalhada nas escolas". (Professor 2)

Mesmo em menor proporção, porém também presente nos discursos dos professores entrevistados, os limites ausência de cursos de capacitação, falta de apoio material e físico e difícil aceitação discente representaram 33,5\% das respostas. Em menor proporção, foram apontados como limites a maneira brusca com que foi feita a mudança e o atraso na entrega dos cadernos do professor.

"[...] Diversificou tanto que não teve uma preparação dos professores, não teve uma qualificação e tem muitas propostas que são muito difíceis de serem aplicadas". (Professor 6)

"O problema é que agente vê a falta de material necessário dependendo da modalidade". (Professor 4)

\section{A NOVA PROPOSTA CURRICULAR E AS AULAS DE EDUCAÇÃO FÍSICA}

Destinarei as páginas a seguir para refletir, esclarecer e tecer comentários sobre a Proposta Curricular de Educação Física destinada a toda rede pública do Estado de São Paulo a partir do seu modelo teórico e da sua execução.

\section{- O modelo teórico}

Independente do modelo teórico utilizado, assim como sua qualidade, a NPC de Educação Física é conseqüência de uma luta que se travava desde a década de 1980 com a finalidade de romper com o paradigma da aptidão física. Dessa forma, todo o referencial teórico vinculado ao campo das ciências humanas e sociais ${ }^{7}$ se fortaleceu e viabilizou uma discussão mais profunda acerca de todas as práticas referentes à cultura corporal do sujeito.

Marco de mais essa conquista, a construção e efetivação desta proposta curricular, tem, sem dúvida, muitas contribuições positivas a oferecer à EF. Não raramente, professores da rede estadual de ensino, em conformidade com uma educação física desvirtuada quanto ao seu papel social e muitas vezes cientes das limitações impostas pela sua formação e/ou condições de trabalho, adotam como "proposta pedagógica" o popularmente reconhecido

\footnotetext{
${ }^{7}$ Destacaram-se nesse contexto as contribuições de Soares et al., ${ }^{9}$ Daólio, ${ }^{10}$ Kunz, ${ }^{11}$ Medina, ${ }^{12}$ Bracht. $^{13}$

Conexões: revista da Faculdade de Educação Física da UNICAMP, Campinas, v. 11, n. 1, p. 235-251, jan../mar. 2013.242 ISSN: 1983-9030
} 
como "rola bola", ou seja, os alunos (em sua grande maioria do gênero masculino) limitavam-se ao jogar bola descompromissado com qualquer intencionalidade pedagógica. Ainda assim, tal prática docente permite ao aluno (quase sua totalidade do gênero feminino) o descanso e a apreciação de músicas em aparelhos eletrônicos ${ }^{8}$.

Portanto, numa realidade da educação física escolar na qual as aulas estavam fadadas ao "rola-bola", a nova proposta trouxe contribuições significativas. A primeira delas, e a mais significativa no meu entendimento, foi, em concordância com os sujeitos entrevistos, justamente romper com está prática dando ao componente curricular Educação Física uma direção (por conta da sistematização dos conteúdos) e um maior grau de importância, reconhecimento e comprometimento, sobretudo pela mudança de postura dos professores e diversificação dos conteúdos a serem trabalhados.

Concordo com as palavras de um dos seus elaboradores que valoriza a construção de uma proposta. Bem ou mal, ela é uma proposta que vem pra dar um caminho a quem está trabalhando no dia-dia com a educação física escolar.

"Eu acho positivo por ser uma proposta, visto que a Educação Física sempre careceu de uma organização dos conteúdos. Bem ou mal, a gente tem uma proposta a partir da qual agente pode trabalhar" (Entrevistado Jocimar Daolio).

Dessa forma, apesar de não apontar ainda as características e qualidade do modelo teórico utilizado, vejo ser de grande valia à superação desta prática docente vigente na educação física escolar.

O modelo teórico de uma proposta política pedagógica é o alicerce e, portanto, fundamental para garantir a sua qualidade. Como supracitado, o conceito de cultura corporal, apesar de bastante disseminado na EF, pode ser compreendido de maneiras distintas conforme o referencial teórico utilizado. Certamente tal conceito seria entendido diferentemente se utilizado por uma abordagem histórico-crítica, ou cultural ou crítica

\footnotetext{
${ }^{8}$ Informações obtidas em experiências ao longo de cinco anos como docente da rede publica estadual paulista. Neste período passei por seis escolas, nas quais pude observar, diagnosticar e ouvir comentários de colegas da área e equipe gestora que sustentem tais informações.

Conexões: revista da Faculdade de Educação Física da UNICAMP, Campinas, v. 11, n. 1, p. 235-251, jan../mar. 2013.243 ISSN: 1983-9030
} 
emancipatória. Entretanto, por não ser objetivo deste estudo, será elucidado a seguir somente o conceito de cultura presente na proposta curricular em questão.

Ao identificar e analisar o modelo teórico utilizado para construir a Proposta Curricular nota-se que a concepção de EF presente neste material passa pelo Esporte, Ginástica, Luta, Atividades Rítmicas e o Jogo como conteúdos culturais relacionados ao movimentar-se humano. Para tanto, se sustenta em dois conceitos chaves: O Se-Movimentar e Cultura de Movimento. Enquanto o primeiro caracteriza-se pela expressão de uma cultura de movimento, sendo a relação que o sujeito estabelece com esta cultura a partir de seu repertório, sua história de vida e vinculações sócio-culturais, o conceito de Cultura de Movimento, já bastante difundido na educação física, porém entendido de distintas maneiras conforme o referencial teórico, caracteriza-se pelo conjunto de significados, símbolos e códigos que se produzem e reproduzem dinamicamente nos Jogos, Esportes, Danças, Lutas e Ginásticas, os quais influenciam, delimitam, dinamizam e/ou constrangem o se-movimentar dos sujeitos. ${ }^{7-8}$

A idéia básica da proposta surge, por influência maior de Mauro Betti, a partir da abordagem critica emancipatória de Kunz, ${ }^{11}$ centrada na idéia do Se-movimentar, compartilhando-a com a idéia de Cultura de Movimento. Este último conceito claramente mais próximo aos trabalhos das últimas duas décadas de Daolio ${ }^{10}$ calcados na antropologia. Vale ressaltar que Kunz preferiria o termo cultura do movimento, visto que não simpatiza com cultura de movimento e muito menos cultura corporal. Os autores, Mauro Betti e Jocimar Daolio, incorporaram em Betti et al. ${ }^{7-8}$ os dois conceitos dando-lhes uma grande compatibilidade.

No Se movimentar, o Se está colocado propositalmente antes para dar uma idéia de o sujeito que se movimenta. Não é qualquer movimento, e sim o seu movimento. O movimento próprio do sujeito, mas movimento esse que faz parte de um certo contexto, certo meio, de uma cultura de movimento [...] Movimento que faz sentido e tem uma série de significados. ${ }^{7-8}$

Ao passo que no ensino fundamental a finalidade da proposta é diversificar, sistematizar e aprofundar as experiências do se-movimentar no âmbito da cultura de movimento, no ensino médio pretende-se propiciar aos alunos a compreensão do Jogo, Esporte, Lutas e 
Atividades Rítmicas como fenômenos sócio-culturais, sintonizando-os com temas do nosso tempo e das vidas dos alunos, ampliando os conhecimentos no âmbito da cultura de movimento, perspectivando a construção de uma autonomia crítica e auto-crítica. ${ }^{7-8}$

Um fato que prejudicou severamente a execução da proposta foi à maneira como os conteúdos foram selecionados, organizados e sistematizados. A seleção pouco considerou as particularidades regionais do nosso Estado, ou seja, foram propostas atividades e conteúdos iguais para escolas de regiões diferentes com conseqüentes hábitos culturais diferentes.

Por outro lado, a sistematização dos conteúdos enunciada nos cadernos do professor, em meio a um currículo comum criado à rede, apesar de suas limitações, permite ao aluno que mudou de escola não se prejudicar, dando assim continuidade ao seu processo de aprendizagem. Dessa forma, todos os alunos que, apesar de estudarem em escolas diferentes (situadas em uma mesma cidade ou não), cursam as mesmas séries, terão o mesmo conteúdo conforme o cronograma bimestral proposto pelo caderno do professor.

Em relação à organização dos conteúdos, creio que ficaram muito dispersos e sobrepostos. Como é possível trabalhar com qualidade em um bimestre (isso para não falar meio bimestre em virtude do atraso da entrega do material), conteúdos como Jogo x Esporte, Jogos Cooperativos, Jogos pré-desportivos e Jogos Competitivos para alunos de uma $5^{\text {a }}$ série? Dessa maneira, ao fim do seu processo de aprendizagem, os alunos conhecerão de tudo, mas saberão de nada!

Por fim, quanto aos princípios na organização curricular, compartilho das proposições de Soares et al. ${ }^{9}$ ao entender que o processo de ensino/aprendizagem se dará de modo mais qualitativo se desenvolvido a partir de uma lógica dialética e não por meio da lógica formal como, por vezes, apresentada nesta proposta. Isso, pois a lógica formal - caracterizada pela fragmentação, estaticidade, unilateralidade, etapismo, linearidade, terminalidade e inculcação - nos remete à formação do indivíduo isolado enquanto que a lógica dialética cerceada pela totalidade, movimento, contradição, salto qualitativo, espiralidade, provisoriedade e produção - nos remete à formação do sujeito histórico. 


\section{- A execução/implementação}

No processo de construção da Proposta, a grande falha de seus gestores e organizadores, foi não promover uma interlocução adequada com os professores da rede. Seria importante, como apontado por um dos professores entrevistados neste estudo, ampliar o debate para os demais pesquisadores da educação física e, juntamente com os professores da rede pública e os organizadores da proposta, criarmos uma proposta coletiva que atenda às necessidades de todos.

Assim, muito pouco se sabe da realidade que os docentes enfrentam, das suas necessidades e de seus alunos, e das condições humanas e materiais para implementação da proposta. Tal fato, por sinal, foi também alvo de críticas dos próprios professores articuladores da proposta.

"Não houve, por parte da Secretaria (é uma crítica minha que eu fiz lá inclusive), uma intenção de consulta aos professores". (Entrevistado Jocimar Daolio)

"Nós achávamos que iríamos ouvir os professores. Nós precisávamos ouvir os professores! Se são todos eles, visto que são quase $6.000 \mathrm{em}$ toda rede, pelo menos grupos deles ou seus representantes como os ATP's" (Entrevistado Jocimar Daolio)

Não obstante, a ausência de diagnóstico das escolas públicas estaduais é facilmente detectada ao nos depararmos com sugestões de aulas nas videotecas das escolas, laboratórios de informática, pista de atletismo entre outras. São raras, se é que existem, escolas que disponham de tal infraestrutura.

Por sua vez, um dos professores responsáveis pela elaboração da Proposta, ao se eximir da responsabilidade (corretamente, no meu entendimento) de fornecer recursos materiais, físicos e didáticos necessários para o cumprimento da proposta, defende-se por meio do seguinte discurso:

"Uma proposta tem que mirar num ideal... Não posso fazer uma proposta para quem tem só uma bola murcha para dar aula. Não cabe a mim ir atrás de mais bolas". (Entrevistado Jocimar Daolio) 
Por outro lado, se a proposta partiu do Governo do Estado de São Paulo, ele deveria estar ciente das necessidades dos professores e das exigências da proposta para que sua execução se desse com qualidade e como pretendido a priori.

O conteúdo desta proposta difere-se, em certa medida, daquilo desenvolvido e trabalhado na maioria dos cursos de graduação em EF no país. Vale ressaltar que os atuais professores efetivos da Rede Pública graduaram em períodos anteriores às novas diretrizes curriculares fundamentadas pelo parecer 58 da resolução 07 de 2004. Este fato em si implicaria num processo de formação continuada do corpo docente previamente ao início do desenvolvimento da Proposta (iniciativa que passou longe de se concretizar). Formação essa, valorizada também pelos articuladores da proposta.

\footnotetext{
"Achávamos que haveria uma série de cursos. Cursos presenciais e encontros tendo a CENP um papel chave nisso para formar núcleos e viajar pelo Estado todo dando cursos. Isso não aconteceu!" (Entrevistado Jocimar Daolio)
}

É de praxe na educação pública paulista o surgimento (de certa forma inesperada, visto que não contou com a participação dos professores da rede) de uma série de propostas e tarefas a serem imediatamente executadas nas escolas sem que antes os professores tenham conhecimento e estejam devidamente preparados para desenvolvê-las. Sem dúvida, mudar a relação de imposição destas propostas e principalmente promover uma formação continuada a todos os professores da rede seria um grande passo na direção da oferta do ensino público de mais qualidade.

A partir da implementação da Proposta, os professores tiveram que diversificar os conteúdos indicados, aumentando-se a necessidade de melhores planejamentos e conhecimento das atividades. Muitos dos professores ainda ativos, em virtude de não terem tido acesso a este conjunto de possibilidades e pela ausência de formação continuada, não possuem conhecimento - quando possuem, são muito superficiais - dos conteúdos 
propostos ${ }^{9}$. Diante disso, vê-se a necessidade de ampliar o conhecimento do corpo docente e contribuir para uma formação continuada de qualidade, fato que passou longe de se efetivar. Como característica da atual gestão da SEE/SP, excluíram-se os cursos de capacitação - importantes no meu entendimento para apreensão de conhecimento e troca de experiências entre os professores - apostando nos cursos à distancia. Como alternativa, foram criadas as vídeo-aulas, mas concordo com as palavras de Jocimar Daolio ao achá-las uma forma de capacitar os professores de modo rápido, mas limitado, pois não substitui um curso presencial.

O caderno do professor, apesar da sua qualidade aparente, apresenta algumas limitações. A qualidade do material, com boa aparência, boas figuras ilustrativas e bons exemplos de atividades, acabam ficando pormenorizadas quando contrastadas com textos muito amplos e conceitos utilizados no Ensino Superior. Dificulta-se assim a compreensão do aluno a respeito do conteúdo a ser trabalhado. Entretanto, essa não é a opinião do professor Jocimar Daolio pois:

“[...] Nele (o caderno do professor) não caiu um texto hermético e acadêmico dificultando a leitura e entendimento dos professores e nem caiu um receituário de atividades práticas.” (Entrevistado Jocimar Daolio)

Por outro lado, apesar de não se caracterizar como um livro didático, os cadernos dos professores os auxiliam, e muito, no planejamento e execução das suas aulas visto que contam com uma série de sugestões e exemplos de atividades, textos, metodologias e avaliações. Desde meados de 2009 a rede passou também a contar com o caderno do aluno: Materiais que sirvam como livros didáticos para os alunos, com textos, exercícios e propostas de atividades. Esta, sem dúvida, foi uma iniciativa de grande valia, visto que carecemos de livros desta natureza para a Educação Física. Entretanto, é de gerar muita desconfiança e crítica o fato dos professores que articularam toda a proposta de Educação Física estar ausentes deste processo, cabendo a outra equipe a sua elaboração.

\footnotetext{
${ }^{9} \mathrm{~A}$ diversidade dos conteúdos, quando relevada à formação dos professores, é muito grande. Gostaria muito de conhecer a Faculdade de EF no Brasil que dê conta de formar um professor para trabalhar, com competência, com conteúdos como Esgrima, Street-Dance, Badminton, entre outros. 
Portanto, quase toda a crítica que manifesto em relação à NPC refere-se à maneira como se deu sua implementação/execução. Por conta da necessidade de cumprir prazos estabelecidos pela própria SEE/SP, os materiais (Revista do Professor e Jornal do Aluno ${ }^{10}$ ) chegaram às escolas no inicio do ano letivo de 2008 sem nenhuma preparação previa dos professores, pegando-os de surpresa sem tempo para conhecer melhor a proposta pedagógica, o material e as atividades a serem desenvolvidas. Fato merecedor de bastante crítica e pauta constante nas reivindicações dos professores e seus sindicatos representantes estão o curto período para discussão, planejamento e construção dos planos de ensino e de aula. Como se não bastassem às dificuldades já impostas, os cadernos dos professores chegam às escolas e aos professores com muito atraso atrapalhando severamente o planejamento para o bimestre, semestre e ano letivo.

A pressa como se deu a implementação da proposta curricular pode atrapalhar seus resultados futuros que possuíam, por meio de uma implementação mais qualificada, perspectivas melhores. $\mathrm{O}$ meu entendimento é que deveria começar a ser desenvolvida somente nas séries iniciais de cada ciclo de ensino. Justifico tal opção por entender que essa mudança de entendimento sobre currículo e metodologia de aula não pode ser processada de modo tão brusco/rápido, visto que exige uma adaptação por parte dos professores e principalmente pelos alunos. Assim, no ano de 2008 , somente a $5^{\text {a }}$ série do Ensino Fundamental e o $1^{\mathrm{o}}$ ano do Ensino Médio desenvolveriam a proposta. Em 2009, $5^{\mathrm{a}}$ e $6^{\mathrm{a}}$ series do ensino fundamental e $1^{\circ}$ e $2^{\circ}$ ano do ensino médio e assim por diante até que todas as series fossem contempladas.

Outro ponto a ser enfatizado em relação à deficiência na execução da proposta está a falta de apoio didático e de recursos físicos e materiais que possibilitem o desenvolvimento eficaz dos conteúdos e atividades sugeridas. Propõem-se uma aula nas videotecas, laboratórios de informática, pistas de atletismo, sendo que são raros nas escolas públicas estaduais (se é que existem) estes espaços como recurso pedagógico. Sugerem-se uma aula

\footnotetext{
${ }^{10}$ Em uma tentativa de ampliar o interesse dos alunos aos estudos, a SEE/SP lançou um material de recuperação de aprendizagem de boa qualidade em forma de jornal com atividades didáticas interessantes em que todas as disciplinas estavam contempladas, entretanto com prioridade aos conhecimentos de ordem matemática e escrita.
}

Conexões: revista da Faculdade de Educação Física da UNICAMP, Campinas, v. 11, n. 1, p. 235-251, jan../mar. 2013.249 ISSN: 1983-9030 
de salto em altura ou salto com vara, sendo que são raras também as escolas que possuem respectivamente um colchão de aterrissagem e vara específica para sua prática com segurança. São ainda propostas atividades que se subentende a existência de salas específicas para ginástica (com espelho e equipamentos) e lutas (com tatame e acessórios). Muitos outros exemplos semelhantes que apontem a ausência de apoio didático e recursos materiais e físicos poderiam ser explicitados. Não que o problema seja evidenciado no momento em que são propostas estas aulas e atividades, mas sim ao não oferecer condições às escolas e professores para efetivar e "fazer acontecer" essas proposições.

Por fim, ao destacar a importância e responsabilidade desta iniciativa política, valorizo o trabalho de seus articuladores e pensadores e direciono minhas palavras na mesma direção de Jocimar Daolio:

\footnotetext{
"Uma proposta feita pela rede estadual de São Paulo tem por si só uma força e repercussão, porque São Paulo tem uma rede de quase 6.000 escolas e qualquer coisa que se faça nesta dimensão repercute nacionalmente." (Entrevistado Jocimar Daolio)
}

Enfim, está claro que a NPC/SP, implementada a partir de 2008 - e em 2009 efetivada como Currículo Oficial - apresenta grandes limitações, mas também várias virtudes. Julgo ser importante que trabalhemos para superar tais limitações e aprimorar ainda mais suas virtudes a fim de proporcionar à população uma educação pública de qualidade e uma educação física consciente de seu papel social!

\section{REFERÊNCIAS}

${ }^{1}$ VALENTE, I. Premiação e castigo na Educação. Folha de São Paulo. São Paulo, 14 mar. 2008. Caderno Opinião.

${ }^{2}$ FOLHA ONLINE. Maria Helena Guimarães de Castro assume Secretaria de Educação de SP. Folha online. Publicado em 24 de Julho de 2007. Disponível em: <http://www1.folha.uol.com.br/folha/brasil/ult96u314689.shtml>. Acesso em: 24 jul. 2007. 
${ }^{3}$ FINI, M. I. (Coord.). Proposta curricular do Estado de São Paulo: Educação Física. São Paulo: SSE, 2008.

${ }^{4}$ CAStro, M. H. G. Um convite à boa educação. Folha de São Paulo, São Paulo, 18 fev. 2008. p. A03.

${ }^{5}$ DARIDO, S. et al. A educação física, a formação do cidadão e os parâmetros curriculares nacionais. Revista Paulista de Educação Física, São Paulo, v. 15, n. 1, p. 17-32, 2001.

${ }^{6}$ SILVEIRA, S. Proposta curricular de $1^{\text {a a }} 4^{\text {a }}$ série do ensino fundamental. Disponível em: <http://cenp.edunet.sp.gov.br/index.htm〉. Acesso em: 8 fev. 2010.

${ }^{7}$ BETTI, M. et al. Caderno do professor: Educação Física, ensino fundamental. São Paulo: SEE, 2008a.

${ }^{8}$ BETTI, M. et al. Caderno do professor: Educação Física, ensino médio. São Paulo: SEE, 2008b.

${ }^{9}$ SOARES, C. L. et al. Metodologia do ensino na Educação Física. 14. ed. São Paulo: Cortez, 2008.

${ }^{10}$ DAOLIO, J. Educação Física e o conceito de cultura. 3. ed. Campinas: Autores Associados, 2010.

${ }^{11}$ KUNZ, E. Transformação didático-pedagógica no esporte. Ijuí: Ed. da Unijuí, 1994.

${ }^{12}$ MEDINA, J. P. S. A Educação Física cuida do corpo... e "mente". 25. ed. Campinas: Papirus, 2010.

${ }^{13}$ BRACHT, V. Educação Física e ciência: cenas de um casamento (in)feliz. 3. ed. Ijuí: Ed. da Unijuí, 2007. 
Recebido em: 17 maio. 2012

Aceito em: 18 nov. 2013

Contato: Rafael Moreno Castellani

Rafael.moreno@uol.com.br 